\title{
Metodología dialógica e interdisciplina en la extensión universitaria. Reflexiones acerca de una experiencia
}

\author{
Dialogical Methodology and Interdiscipline in University \\ Outreach. Reflections On an Experience
}

LUCÍA TROTTA Y PAULA SOZA ROSSI

Universidad Nacional de La Plata, Argentina

RECEPCIÓN: 3O/II/2OI2 · ACEPTACIÓN: 22/05/20I3

RESUMEN El trabajo es el resultado de nuestras reflexiones sobre la metodología dialógica y la conformación de equipos interdisciplinarios en procesos de investigación-acción. Las mismas surgieron a partir de una experiencia de extensión universitaria desarrollada en la Universidad Nacional de La Plata, Argentina, en conjunto con la Comisión Provincial por la Memoria (CPM) y la Asociación de Trabajadores del Estado (ATE) de la Provincia de Buenos Aires. El proyecto buscaba el acceso, apropiación y resignificación colectiva de los documentos pertenecientes al archivo de la ex Dirección de Inteligencia de la Policía de la Provincia de Buenos Aires (DIPBA) en posesión de la CPM. Es decir, un encuentro entre esos documentos que contenían parte de la historia argentina de persecución, represión y prácticas de resistencias, y sus protagonistas. El trabajo busca identificar los nudos problemáticos y las potencialidades de la experiencia, así como reconstruir la apuesta metodológica que se constituyó a partir de la disposición al diálogo y de la conformación de un nos-otros. En este proceso se analiza la presencia de una perspectiva dialógica en la conceptualización de la noción de extensión; en la opción metodológica por la investigación-acción participativa y sus tensiones presentes en el campo; en la forma de pensar y 
actuar interdisciplinariamente construyendo un otro extensionista; y en la decisión a partir de las necesidades situadas planteadas por los trabajadores y las trabajadoras de incorporar específicamente el diálogo intergeneracional e intergénero. Una posición que nos permitió un diálogo entre sujetos participantes de la experiencia de extensión y la elaboración colectiva de los denominados procesos de «re» (Vasilachis, 2007). Redefinición de la identidad, redefinición discursiva ante la mirada de los otros (la DIPBA) y una redefinición de la memoria colectiva de los trabajadores y las trabajadoras del sindicato a partir de una reconstrucción histórica colectiva. Por último, se plantean los obstáculos y elementos facilitadores que encontramos en todo el proceso, de modo de realizar un aporte que ilumine algunos aspectos para llevar adelante otras experiencias de extensión universitaria exitosas.

PALABRAS CLAVE Extensión universitaria, metodología dialógica, interdisciplina, investigación-acción participativa.

ABSTRACT This work is the result of our reflections on dialogical methodology and the formation of interdisciplinary teams in research-action processes. They arise from an experience in university outreach carried out by Universidad Nacional de La Plata, Argentina, jointly with the Provincial Commission for Memory (CPM) and the State Employees' Association (ATE), Province of Buenos Aires. The object of the project was access to, and appropriation and collective resignification of, documents from the Archive of the ex-Police Intelligence Directorate of the Province of Buenos Aires (DIPBA), held in custody by the CPM. In other words an encounter between these documents - which contain a part of Argentina's history marked by persecution and repression, and also by resistance - and their protagonists. The work seeks to identify the problem nodes and the potential of the experience, and to reconstruct the methodological challenge created by the disposition to dialogue and the formation of a relation of us-others. In this process we analyze the presence of a dialogical perspective in the conceptualization of the notion of outreach; in the methodology chosen for the participative research-action and its tensions in the field; in the application of interdisciplinary thought and action to construct an other outreacher; and in the decision based on the needs tabled by workers to specifically incorporate inter-generation and inter-gender dialogue. This position allowed us a dialogue between the subjects who participated in the outreach experience and the collective creation of the so-called «re»-processes (Vasilachis, 2007): redefinition of identity, redefinition of discourse under the eyes of 
the others (DIPBA), and redefinition of the collective memory of the union workers from a collective reconstruction of history. Finally, we present the obstacles and facilitating elements which we found throughout the process, enabling our contribution to illuminate certain aspects. These will help in carrying out further successful university outreach experiences.

KEYWORDS University outreach, dialogical methodology, interdiscipline, participative research-action.

\section{Introducción}

Este trabajo es el resultado de una serie de reflexiones sobre la metodología dialógica y la conformación de equipos interdisciplinarios en procesos de investigación-acción. Las mismas surgieron a partir de una experiencia de extensión universitaria ${ }^{1}$ desarrollada en la Universidad Nacional de La Plata, Argentina, en conjunto con la Comisión Provincial por la Memoria (CPM) y la Asociación de Trabajadores del Estado (ATE) de la Provincia de Buenos Aires. El proyecto buscaba el acceso, apropiación y resignificación colectiva de los documentos pertenecientes al archivo de la ex DIPBA, ${ }^{2}$ es decir, un encuentro de los y las protagonistas con esos documentos que contenían parte de la historia argentina de persecución y represión política, pero también sus prácticas de resistencias. En este sentido, durante el proyecto se generó un espacio de debate y aprendizaje mutuo sobre el rol de las diferentes disciplinas y los sujetos destinatarios de la experiencia en la co-construcción de conocimiento social sobre nuestra historia reciente. Esto fue posible en la medida en que fueron considerados los ritmos propios de una metodología crítica, donde, al decir de Vasilachis (2007), la posición del sujeto cognoscente es revisada para

I. El proyecto de mención se tituló «Los sindicatos bajo la mirada de la Dirección de Inteligencia de la Policía de la provincia de Buenos Aires (DIPBA): hacia una construcción colectiva de la historia de la represión a las organizaciones gremiales» y se desarrolló durante los años 2006 y 2007.

2. Dirección de Inteligencia de la Policía de la Provincia de Buenos Aires. El Archivo se encuentra en guarda de la CPM desde el año 200 I y contiene informes de inteligencia y otros documentos producidos y recopilados por la DIPBA desde I 957 en su función de detectar y perseguir en forma sistemática a organizaciones políticas, sociales, religiosas, estudiantiles y gremiales. 
poder acercarnos de manera innovadora al sujeto conocido. De allí que una metodología dialógica resultó ser la adecuada para nuestro objetivo de accióntransformación, de los otros/as como de nosotros/as mismos/as (Fals Borda, I979). Las reflexiones y escritura a posteriori nos permiten entonces dar cuenta de manera más clara lo que constituyó nuestro eje articulador: vincular en la investigación-acción participativa el proyecto de extensión universitaria, del cual formamos parte.

\section{Diálogos en acción}

El diálogo se fue constituyendo en el eje vector del proyecto. En primer lugar, desde el aporte que hicieran los/as compañeros/as que provenían del área de educación, en la manera de conceptualizar a la extensión universitaria como comunicación-acción. En segundo lugar, en la forma de co-construir la interdisciplina para la conformación del equipo de trabajo. Aquí, la disposición a escuchar al otro, en tanto portador de un saber específico, fue posible a partir de un punto unificador representado por la decisión ideológica y cognitiva de intentar una investigación-acción transformadora.

Por otra parte, el diálogo también estuvo presente en la vinculación con los/ as trabajadores/as del sindicato, en todo el proceso que requirió armar el proyecto, elegir la metodología y técnicas de trabajo y planificar las actividades de manera conjunta. Ello permitió que éstas pudieran ir ajustándose en el transcurso del proyecto en función de las necesidades situadas de los/as trabajadores/ as. El ajuste se realizó resignificando aquellas técnicas de carácter clásico inscritas en el paradigma tradicional positivista (exposición histórica), como a las llamadas técnicas participativas (observación participante, dispositivo taller), cuidando que la puesta en práctica de éstas no reprodujera una relación de poder hacia el polo del sujeto cognoscente (Vasilachis, 2007; Fals Borda, I979).

Por último, a partir del diálogo construido principalmente con las referentes del Área de Derechos Humanos del sindicato que promovieron el proyecto, hubo dos necesidades que ellas mismas nos exteriorizaron a las que prestamos especial atención: la de dar sonoridad a la voz de las mujeres de y los/as jóvenes de la organización. Es por ello que parte esencial de nuestro trabajo fue promover el diálogo intergeneracional e intergénero.

Decidimos por todo esto organizar la estructuración del presente trabajo en función de la multiplicidad de diálogos que tuvieron lugar en el desarrollo de la experiencia de extensión universitaria. 


\section{Primer diálogo: extensión como comunicación y reconocimiento del otro}

Comprender un proyecto de extensión universitaria en tanto instancia dialógica de comunicación-acción implicó una predisposición crítica hacia la noción de extensión y la exigencia de la definición de un objeto, ${ }^{3}$ para llegar a convertirse también en un resultado de la experiencia.

Quizás porque en la elección de ese objeto ya se nos aparecían personas con las cuales nos habíamos vinculado previamente, en tanto representantes del sindicato durante nuestro trabajo en el archivo de la ex DIPBA, las habíamos visto emocionarse, enojarse, asombrarse con los documentos pertenecientes a la inteligencia policial realizada sobre el sindicato y sus trabajadores a lo largo de décadas, por lo que traducirlos/as en meros objetos destinatarios de nuestra tarea nos generaba desde un principio irritación y controversia.

De este modo, nos propusimos inscribir el proyecto en una perspectiva que entiende a la extensión como comunicación, y donde el diálogo es el principal medio para que se dé una experiencia significativa para todos los actores intervinientes. Sin desconocer, por otro lado, la propia historicidad contenida en la noción de extensión universitaria. La misma se constituye luego del movimiento de Reforma Universitaria de r9 8 como uno de los pilares, junto con la docencia y la investigación, de la universidad latinoamericana y es un término cuya definición y significación fue y es un espacio de disputas. Originado en Córdoba, Argentina, el movimiento reformista cristalizó sus principios en formas de organizar e imaginar la universidad latinoamericana. Entre los principios de autogobierno, representación de estudiantes y graduados en los órganos de gobierno, modernización de la enseñanza, libertad de cátedra y compromiso con la cuestión social, el último será central en todos los movimientos estudiantiles posteriores, pero también derivará en corrientes intelectuales y movimientos políticos en varios países de Latinoamérica (Krotsch, 200I: I30).

La extensión universitaria —actividad «extramuros»— será el área específica para desarrollar este vínculo con lo social, donde convivirán una vertiente culturalista, en términos de difundir, extender la cultura de la élite universitaria a los sectores más desfavorecidos; y, por otro, una vertiente que entiende la extensión como un trabajo social, de generación de vínculos solidarios y cola-

3. En los formularios de presentación a concurso de proyectos de extensión universitaria se exige la definición de un objeto de extensión, en tanto destinatario de la acción. 
borativos con el pueblo a partir del encuentro en situaciones concretas para la solución de problemas específicos (Bralich, I994: 40).

La vertiente que primó hasta mediados del siglo XX fue la de una universidad que, consciente de su condición de institución superior del saber y privilegiada, proyectaba sus saberes legítimos al resto de la sociedad, entendiendo a los destinatarios como simples depositarios, y definiendo unilateralmente el contenido y el alcance de esa proyección (Tünnermann Bernheim, 200I: 5). Así los primeros reformistas proclamaban una universidad pública de libre acceso para las mayorías, pero también promovían una concepción de la extensión, de ese lazo de la institución universitaria con esas mayorías, a partir del dictado de conferencias y charlas a los/as trabajadores/as para que pudieran escuchar la palabra de la universidad (Bralich, I994).

En las décadas del cincuenta y sesenta las universidades latinoamericanas fueron institucionalizando sus programas de extensión y al mismo tiempo se fue produciendo un proceso de apertura en la propia concepción. Tünnermann Bernheim (200I) identifica dos aportes esenciales en la transformación de la conceptualización: la Segunda Conferencia Latinoamericana de Extensión Universitaria y Difusión Cultural realizada en México en I972, y los aportes de Paulo Freire en su análisis crítico de la educación y la pedagogía dominante, funcional al sistema de opresión capitalista. En el primer caso, luego de la conferencia citada, se identificaron distintas respuestas en el vínculo universidadsociedad, entre ellas el cuestionamiento del statu quo y el aporte de desencadenar procesos de cambio en alianza con los sectores oprimidos y otras fuerzas de cambio. ${ }^{4}$ Por otro lado, Paulo Freire aportó un análisis crítico del término extensión y propuso una forma de relación entre distintos espacios de saber a partir de la noción de comunicación (Freire, 200I).

En su reconocido libro Pedagogía del oprimido (1970), Freire critica la educación bancaria, es decir, aquella educación en la que el educador deposita

4. En la actualidad si bien persiste el término extensión, las universidades argentinas tienden a definirla como una actividad que pretende que los conocimientos adquiridos en las distintas etapas de la formación académica se vinculen con la sociedad. La idea es que por medio de la extensión, la universidad transmita a otros actores sociales parte de sus conocimientos y que, a la vez, estos saberes se vean enriquecidos y ampliados por el aporte que dichos actores puedan realizar sobre el tema en cuestión, basados en un paradigma de democratización de los saberes y de interacción creativa entre ambos espacios. Para más información, véase <http://www.unlp.edu.ar/extension>. 
en los educandos un conocimiento totalmente desvinculado de la realidad y, a través de esta pasividad impuesta, se logra mantener el statu quo, ya que los oprimidos tenderán a adaptarse al mundo en lugar de transformarlo. Freire propone en cambio una educación problematizadora, que se centre «en que los hombres sometidos a la dominación, luchen por su emancipación» (Freire, I 985 : 99). La educación como práctica de la libertad supone una metodología basada «en la palabra generadora, cuyo sentido fundamental es que surge de una tarea de discusión y reflexión colectiva, de la cual nace una relación dialógica (basada en el diálogo igualitario y mutuamente enriquecedor) entre educador y educando» (Puiggrós, I987: 54). Es necesario, en este caso, que el educador asuma una postura radical democrático-revolucionaria y para ello que entienda a la educación como un acto de conocimiento, partiendo de la comprensión de los educandos para alcanzar una comprensión más exacta de la realidad (Freire, 1985). Esto no implica para Freire un mero proceso de concientización de los sectores populares, sino también proveerlos de instrumentos útiles, como el dominio de elementos de la cultura dominante y el desarrollo de una conciencia crítica, en la lucha contra la opresión (Bralich, I994: 72).

De allí que para Freire el concepto de extensión, que supone una relación entre un sujeto que extiende y un objeto que recibe bajo una lógica mecanicista, desde la sede del saber hasta la sede de la ignorancia, no se corresponda con la idea de una educación liberadora, ya que «transformando al hombre en casi una cosa, lo niegan como un ser de transformación del mundo. Además de negar [...] la formación y la constitución de conocimientos auténticos. Además de negar la acción y la reflexión, verdaderas, a aquellos que son objetos de tales acciones» (Freire, 200I: 2I). Asimismo, postula una concepción dialógicacomunicativa del conocimiento que, en tanto acción de los sujetos, implica en el mismo proceso de conocimiento una acción transformadora de la realidad (Freire, 200I: 28). Aprender supone además un proceso de concientización, es decir, de apropiación crítica de nuestro lugar en el mundo para transformarlo (Freire, 200I: 40).

El acto cognoscitivo incluye sujetos cognoscentes, un objeto a conocer, pero fundamentalmente la comunicación entre éstos. Por lo que no es posible entender el pensamiento sin su doble función: cognitiva y comunicativa. En palabras del autor: «La educación es comunicación, es diálogo, en la medida en que no es la transferencia del saber, sino un encuentro de sujetos interlocutores, que buscan la significación de los significados» (Freire, 200I: 77). En esta dimen- 
sión revolucionaria que contiene la concepción dialógica, Fals Borda (I979: 294), en coincidencia con Freire, señala que la apropiación de conocimiento implica la resignificación de lo actual en un proceso histórico. Ambos autores formaron parte del campo de confluencia entre distintas corrientes de pensamiento y disciplinas que entre las décadas del sesenta y el setenta abogaban en toda América Latina por producir conocimientos científicos que permitieran a sectores subalternos de la sociedad comprender críticamente la realidad para transformarla a partir de un diálogo entre saber académico y saber popular (Ortiz y Borjas, 2008: 6I7). Entre las distintas corrientes que convergieron en este campo, aparece una coincidencia en términos epistemológicos: por un lado, postulan que no existe el conocimiento neutral y que es necesario el desarrollo de conocimiento crítico, el cual necesita del acercamiento al conocimiento empírico, práctico, de las bases sociales (en nuestro caso, de los/las trabajadores/as portando conocimiento a partir de su experiencia como tales). Y, por otro lado, enfatizan una dimensión vinculada a la acción que, en la teoría falsbordiana, se constituirá en la investigación-acción participativa (IAP) (Ortiz y Borjas, 2008).

Este nuevo bagaje dentro de las ciencias sociales surge en un contexto epistemológico donde los marcos de referencia o paradigmas tradicionales dejaban ciertos procesos sociales vinculados con una construcción consciente de la historia en la penumbra del conocimiento (Fals Borda, I979: 259). Además, el paradigma naturalista, exaltando la figura de un observador neutral, invisibiliza que el propio observador forma parte del universo a observar e incide en el mismo. Esta condición oscurecida por el canon positivista tenía como consecuencia incluso que técnicas de campo como la "observación participante» y la «observación por experimentación» tendían a conservar las diferencias entre el observador y lo observado. La técnica de la «inserción en el proceso social», en cambio, fue uno de los primeros avances que reconoce el papel protagónico de las masas populares, con la consiguiente disminución del papel del intelectual-observador como monopolizador o contralor de la información científica (Fals Borda, 1979: 262).

Éstos y otros aportes intentarán conformar un paradigma alterno de una ciencia social crítica, donde «la investigación social y la acción política, con ella, pueden sintetizarse e influirse mutuamente para aumentar tanto el nivel de eficacia de la acción como el entendimiento de la realidad» (Fals Borda, I979: 73). 


\section{Segundo diálogo: la investigación acción participativa, un encuentro dialógico}

Una segunda instancia donde el diálogo estuvo presente fue en la elección metodológica. Retomando la idea de la elección ideológica contenida en el «para quién» de Fals Borda, proponemos en pos de una mayor riqueza analítica de la experiencia subdividir este "para quién» en tres instancias que dan cuenta del recorrido metodológico realizado: el «entre quiénes», el «con quiénes» y el «porqué» de nuestra investigación-acción.

La primera instancia, el «entre quiénes», incluye tanto al equipo de investigación-acción como a lo que en jerga tradicional se denominan los/as destinatarios/as de nuestro proyecto de extensión universitaria.

En la constitución del equipo partimos por reconocer la necesidad del aporte del saber de los otros/as, en tanto representantes de las distintas perspectivas disciplinares, como condición en la conformación del punto de mira y de acción para el encuentro con los/las trabajadores/as del sindicato. El mismo se compuso a partir de la participación de graduados y estudiantes provenientes de la sociología, la comunicación social, la historia, la informática y la archivística. Allí, sin duda, que la mayoría perteneciéramos al campo de las ciencias sociales era una condición necesaria pero no suficiente para lograr un encuentro entre todos/as. La co-construcción de lo interdisciplinar se vio reforzada por una disposición a escucharnos y por un punto unificador: la decisión ideológica y cognitiva de intentar hacer una investigación-acción transformadora.

Hubo otra condición que sumó en este sentido: una trayectoria común, un encuentro previo al proyecto y un reconocernos de manera transversal en la condición de trabajadores y/o extrabajadores de la Comisión Provincial por la Memoria, que no sólo aportó en la configuración de nuestra identidad grupal sino también en torno a una formación común: la archivística, que como conocimiento técnico nos permitió identificar y localizar los documentos del archivo en su contexto de producción.

Este reconocimiento marcado por el deseo mancomunado de socializar el acceso de los protagonistas a los documentos de la represión política, facilitó la constitución del marco común, la perspectiva cognitiva, que delimitó el proyecto y que se relaciona con la segunda instancia, la que implica definir el «con quiénes». Coincidimos en adoptar una metodología (también pedagogía) donde los encuentros dialógicos propiciados desde la técnica-taller intentaran resignificar las maneras tradicionales de la relación con los otros/as, donde 
sin substraernos a la responsabilidad de ser personas portadoras de un saber universitario cuidáramos el proceso a través del cual entre todos/as llegáramos a alcanzar un buen sentido gramsciano sobre el tema del proyecto (Fals Borda, I979). La elección entonces de las técnicas de trabajo estuvo desde los inicios orientada a incorporar las distintas necesidades situadas de los/as trabajadores/as, así como sus saberes y sentires en tanto clave para la construcción colectiva de conocimiento.

En tercer lugar y en estrecha relación con las anteriores instancias, definimos el "porqué», cuyo núcleo era socializar los documentos, hacer que los/as trabajadores/as se reencontraran con su agencia histórica como trabajadores/ as en lucha en Argentina, antes, durante y después de la última dictadura militar.

Decidimos adoptar la metodología de la investigación-acción participativa dado que para nosotros/as era la perspectiva que nos permitía respetar la especificidad de un proyecto de extensión, como también acercarnos a aportar de forma, aún acotada, a la construcción de saberes hacia una ciencia alternativa al canon tradicional. Una ciencia crítica de la realidad como de sí misma en cuanto a las maneras en que se construye conocimiento.

Interferencias en el diálogo: tensiones estratégicas de la IAP

Posicionarse desde esta perspectiva supuso hacer frente a varias de las tensiones estratégicas que señala Fals Borda como propias de la IAP y que vivenciamos a lo largo de nuestro proyecto. El desafío epistemológico y la imposición de la acción transformadora serán el marco en el que se dirimirán dichas tensiones sintetizadas por el autor colombiano como tensión teoría-práctica, tensión sujeto-objeto y tensión entre participación y cosmovisión del mundo; y que desarrollaremos a continuación, para más adelante presentar distintos momentos del proyecto en los que tuvimos que enfrentarnos con las mismas.

La tensión entre teoría y práctica. Fals Borda, preocupado por la escisión entre el conocer y el actuar, característico del paradigma dominante de construcción de conocimiento, expresa: "Tratar de vincular el conocimiento y la acción - la teoría y la práctica一, como en el castigo de Sísifo, es un esfuerzo permanente e inacabado de comprensión, revisión y superación sobre una cuesta sin fin, difícil y llena de tropiezos» (Fals Borda, I979: 256). En contra de los paradigmas deductivos, la IAP propone un paradigma holista participa- 
tivo que, siguiendo un pausado ritmo de reflexión y acción, permita ir haciendo ajustes en el camino y cuya validación estará dada por elementos propios del campo, entre ellos, la percepción de los grupos involucrados. La validación en la IAP - a diferencia de las metodologías tradicionales que circunscriben la misma a la obtención de resultados- se realiza por medio de la acción concreta, esto es, que desde el inicio la causa última tiene una dimensión teóricopráctica, donde lo aleatorio de la acción social queda sujeto al marco de la praxis (Fals Borda, I979: 26I). Retomando conceptos aristotélicos, el autor propone una praxis con frónesis o propósito.

La tensión sujeto-objeto. Trascendiendo la dicotomía planteada por el paradigma tradicional, la IAP rescata los vínculos interpersonales mediados por sentimientos, normas, actitudes, opiniones y experiencias diversas, y un camino que implica apreciar la contribución del otro para llegar a una relación sujeto-sujeto de carácter horizontal y simétrica. Este diálogo entre distintos tipos de conocimiento será la base de una participación auténtica, que al mismo tiempo supone una devolución sistemática con el propósito de intercambiar el conocimiento. En este punto el rol del lenguaje es central para garantizar esa comunicación efectiva (Fals Borda, 2008).

El paradigma de la ciencia social crítica estipula entonces que la diferencia entre sujeto y objeto puede reducirse en la práctica de la investigación y para ello es necesario entablar un diálogo con el otro a través de un lenguaje claro, lo que implica formas de publicación y producción intelectual más abiertas (Fals Borda, I979: 287).

La tensión de la filosofía de la participación y la cosmovisión del mundo (Weltanschaung). El marco de la IAP conlleva como supuesto adoptar una actitud empática hacia los demás, denominada «compromiso» o "vivencia», que significa experiencias de vida y participación auténticas. En este camino, deja de ser una metodología de investigación para convertirse en una mirada del mundo sostenida por practicantes sentipensantes dispuestos a luchar por la transformación social.

Junto a Donna Haraway, pensamos que una de las condiciones de posibilidad de una inteligibilidad social que incluya a los otros, y sus pareceres y sentires, implica necesariamente un compromiso emocional del investigador. No excluir las emociones en la construcción de saberes permite traducir conocimientos entre comunidades muy diferentes y diferenciadas en términos de poder (Femenías y Soza Rossi, 20 I I: I 5 ). 


\section{Las tensiones de la IAP en el campo de acción}

La construcción del marco de referencia de nuestra investigación-acción fue una construcción gradual, desordenada, con conceptos que se fueron explicitando y conjugando en el propio proceso mediante el intercambio y aporte disciplinar y experiencial entre los/as integrantes del equipo y con los/as trabajadores/as. Marco de referencia que este mismo escrito nos ayudó a explicitar y que inscribe la técnica-taller que eligiéramos para llevar adelante los encuentros dialógicos en este campo de sentidos.

Identificamos en este proceso la presencia de las tensiones señaladas por Fals Borda, tensiones que fuimos resolviendo en el transcurso de la investigación-acción.

Uno de los propósitos de los talleres era que nuestro conocimiento sobre los procesos históricos, sobre la última dictadura argentina y los documentos de la DIPBA, colaboraran en las reflexiones sobre las prácticas sindicales actuales de los/as trabajadores/as de la ATE.

Lo que buscábamos era propiciar el diálogo entre los sindicatos, su historia y la universidad; para eso necesitábamos las voces de los protagonistas de esos cientos de legajos confeccionados por la DIPBA. El aporte que estas organizaciones tuvieran para hacer, desde sus vivencias específicas y el propio análisis de su historia, resultaba por demás interesante en tanto introducían una mirada todavía ausente en los papeles hallados: el de las propias organizaciones víctimas del espionaje y la persecución (Giménez y otros, 20I2).

Y así, a partir del diálogo comunicativo se producía un nuevo conocimiento resignificando esa historia y, al mismo tiempo, un conocimiento de nuestra propia práctica en el campo de la extensión universitaria.

Ahora bien, llevar a cabo este propósito necesitó de reajustes sobre la marcha. Una anécdota de la experiencia puede dar bien cuenta de la presencia latente de la primera tensión descrita por Fals Borda: como balance del primer taller, en nuestro encuentro posterior con las representantes sindicales, interlocutoras claves desde el inicio del proyecto, se explicitó una demanda puntual: «¿Porqué no nos dan una clase sobre la historia?». En esa demanda se ponía sobre la mesa el hecho de que al querer apegarnos a la generación de un diálogo horizontal no habíamos reparado suficientemente que en la interacción cog- 
nitiva con los/as trabajadores/as, como sujetos conocidos, tenían una representación sobre nosotros/as en tanto universitarios y determinadas expectativas. Esto implicaba una autoridad de saber sobre el período histórico seleccionado para el análisis documental y sobre las características particulares del entramado social en las distintas etapas de nuestra historia reciente. En consecuencia, y gracias al proceso de validación con los otros, preparamos para el segundo taller una exposición que diera cuenta de una contextualización sociohistórica sobre las relaciones de fuerza entre los trabajadores y los sectores dominantes. Caímos en la cuenta que la horizontalidad no la garantizábamos al eludir la responsabilidad que conlleva portar un saber emanado de la universidad como fuente legítima de conocimiento científico.

En nuestro temor inicial queda reflejado el peligro de la asimetría que arrastra determinada técnica enmarcada en un paradigma específico, en este caso el paradigma tradicional de transferencia unilateral de saberes. Como define Fals Borda en relación a la potencialidades y limitaciones de ciertas técnicas de las ciencias sociales:

Hay que poner en su contexto conformista y reconocer sus limitaciones a aquellas técnicas empíricas derivadas del paradigma normal que cosifican la relación social, creando un perfecto divorcio entre sujeto y objeto de investigación, es decir, manteniendo la asimetría entre entrevistador y entrevistado (I979: 264).

Por otro lado, el mismo Fals Borda advierte que ninguna técnica garantiza el logro de los objetivos planificados, como tampoco define al proyecto en sí.

En este sentido, una técnica de exposición más tradicional realizada en un marco específico de comunicación dialógica e identificación de fines comunes, se convirtió en una experiencia compartida, una herramienta analítica en función de las bases y no del investigador, permitiéndonos trascender la dicotomía sujeto-objeto descrita más arriba. Fue fructífero a este fin utilizar un lenguaje claro y preciso que permitió una comunicación efectiva, tanto para la elaboración del material complementario sobre la historia y el archivo de la ex DIPBA, que se distribuyó en cada taller, así como en el diseño y redacción de la publicación colectiva que relata la experiencia. Consideramos que en los talleres realizados se lograron comunicar y articular los distintos saberes, sentimientos y experiencias de los trabajadores/as e integrantes del equipo de extensión, transversalizados por las categorías de género y generación, otro de 
los propósitos del proyecto. Esto permitió la apertura del alcance técnico del trabajo, en nuestro caso dar lugar a la multiplicidad de voces.

La técnica taller fue la que habilitó esa participación auténtica. El taller es una estrategia que se inserta en un espacio de comunicación complejo, de creación de significados y/o negociación de conceptos y que, en la puesta en juego de diversos universos culturales, se construye el sentido y la significación del contenido (Lucarelli, 2000). Para que éste sea viable es necesario alcanzar un resultado en un interjuego entre el tiempo y la organización grupal, donde el aprendizaje termine siendo el resultado de la interrelación entre la producción individual y la producción colectiva. Siguiendo a Lucarelli (2000), podemos decir que todo taller atraviesa distintas fases: una introductoria, donde se anticipa la organización del encuentro y la tarea; una fase del desarrollo propiamente dicho, que conjuga la realización de las tareas por medio de distintas técnicas y modalidades (por ejemplo, el debate en grupos más pequeños, la puesta en común, etcétera); y una fase final llamada de afianzamiento, donde se reelabora la experiencia apelando al marco teórico y reflexionando sobre las particularidades que ésta tuvo. Tanto el proceso de escritura de la publicación final que relata la experiencia, como este mismo trabajo, forman parte de esa etapa.

Por último, el compromiso emocional, condición de posibilidad para involucrarse con los otros, estuvo presente en las reuniones y encuentros con los/ as representantes del sindicato y de las otras instituciones copartícipes, en la producción de materiales y la realización de los talleres, es decir, en todas las instancias del proyecto.

Uno de nuestros propósitos originales era articular puentes entre las distintas instituciones y fomentar la restitución de los lazos sociales entre diferentes sectores, afectados por las políticas neoliberales inauguradas con la última dictadura militar. En este sentido, podemos decir que la empatía y los vínculos generados a lo largo de toda la experiencia, entre nosotros/os y con los otros/ as, marcaron nuestra trayectoria académica y personal.

\section{Tercer diálogo: un encuentro entre nos-otros}

Hemos reflexionado de qué modo en la temática de la interdisciplinariedad, más allá de las expresiones políticamente correctas, en la práctica no pocas veces el vínculo entre disciplinas reproduce una relación una-otra, donde la primera, autolocalizada en la posición de una, interactúa con la otra como un 
texto anfitrión de las diferencias que no conmueven un pensar «autosuficiente y completo». Al decir de Deleuze, si no se revisa el modelo disciplinar soberano, se reproduce la creencia de las disciplinas como reinos poseedores de un aparente poder absoluto.

Para el caso de nuestro proyecto de extensión, la revisión de nuestras formaciones tradicionales — que circunscriben los objetos de estudio y generan limitaciones empobrecedoras - tuvo como condición de posibilidad de diálogo interdisciplinar adoptar los aportes de las epistemologías y metodologías «alternativas» volcadas a la investigación-acción. Así, también repensar las prácticas de construcción de saber-acción implicó incorporar reflexiones de la epistemología del sujeto conocido a la epistemología del sujeto cognoscente.

Adscribiendo al pensamiento de Foucault en cuanto a las disciplinas - como discursos o conjuntos de saberes organizados de acuerdo con modelos científicos de un campo epistémico- el asumir la responsabilidad de la conocida articulación poder-saber nos desafió a replantearnos cuestiones implícitas en las distintas formaciones académicas y prácticas naturalizadas. Por eso para superar las limitaciones de lo que podría llamarse un collage de miradas disciplinares, es requisito la consciente elaboración de un marco general y común donde cada uno/a de los representantes en mirada introspectiva revise conceptos y metodologías propias de su campo. Siguiendo a Ignacio Lewkowicz, construir un nuevo saber común involucra pensar en suplementos que trasciendan el complemento, dado que los primeros generan algo nuevo al destotalizar un saber autosuficiente que concibe al complemento como necesidad transitoria.

En este punto es importante reconocer los aportes del debate multicultural para pensar el diálogo interdisciplinar. Haciendo un paralelo con éste, podemos plantear dos maneras de pensar a las disciplinas y sus relaciones.

Adherir a una concepción del multiculturalismo mosaico, al decir de Benhabib (2006), arrastra consigo la purificación de las diferencias que, circunscritas a las relaciones entre culturas, escamotea la visibilidad de las relaciones intraculturales. Llevado al análisis disciplinar, esta concepción obstaculiza reconocer las diferencias internas al proyectar la diversidad y la divergencia de líneas de pensamiento en las otras disciplinas. En realidad, se niegan los puntos de demasiada proximidad a fin de garantizar una pertenencia «sin conflictos» en el interior de la disciplina propia, donde quedan invisibilizadas las divergencias ideológico-epistemológicas intradisciplinares.

Transferir a las culturas disciplinares la imagen auditiva del multiculturalismo, nos incentiva a tolerar cierto nivel de incertidumbre en relación a las defini- 
ciones de la otra disciplina. El dejar en suspenso las definiciones sobre la otra da lugar a escuchar lo que las demás disciplinas tienen para decir sobre sí mismas.

Para el proyecto de extensión, la construcción del diálogo tuvo como base la confianza generada a partir de la valoración común sintetizada: la disposición a escucharnos. Siguiendo a Fals Borda, entre todos/as — previa revisión de nuestras prácticas disciplinares- pudimos a través del encuentro dialógico co-construir un punto culminante de unificación entorno a la investigaciónacción participativa y al interés común de construir una ciencia social critica.

\section{El otro conocido}

Nos parece pertinente traer a colación la reflexión epistemológica de Irene Vasilachis, reconocida estudiosa de la metodología cualitativa cuya preocupación radica en dar cuenta de la situación de personas en pobreza extrema. Para la autora es imperioso propiciar como actividad persistente una reflexión epistemológica, actividad que ya está presente en la práctica de los investigadores, en la ciencia que "se está haciendo».

Esta reflexión la llevó a revisar los paradigmas que constituyen lo que denomina la epistemología del sujeto cognoscente. Sin desconocer sus méritos en la producción de conocimiento, advierte cómo ésta, al mantener un sentido unidireccional en un vínculo que parte del sujeto cognoscente, no sólo propicia una separación con el sujeto conocido sino que también lo preserva de ser transformado, de ser conmovido (Vasilachis, 2007: 6).

Denominará epistemología del sujeto conocido a aquella que tiene como presupuesto una igualdad esencial de los seres humanos, impidiendo ver en el otro un objeto a ser conocido. Este presupuesto le otorga un papel central al sujeto conocido en la definición de sus aspiraciones, deseos, motivaciones y fines por lo cual la validez de la producción de conocimiento será proporcional a la menor tergiversación de los mismos. La condición para que el sujeto provea conocimiento sobre sí mismo es que se produzca un interacción comunicativa, una interacción cognitiva. En palabras de la autora, «de lo que se trata es de considerar el resultado del proceso de conocimiento como construcción cooperativa en la que los sujetos esencialmente iguales realizan aportes diferentes» (Vasilachis, 2007: II). En esta interacción hay una mediación representativa en ambos sentidos de los sujetos que establecen el diálogo. Por un lado, el científico apelará a aquellas teorías generales que intentaron describir, explicar e interpretar la acción de los sujetos a lo que refiere su investigación, mientras 
el sujeto conocido, desde sus representaciones, no sólo situará al investigador y su actividad, sino que se posicionará frente a él. Esta metodología destaca como central la disposición del investigador no sólo para encontrar al sujeto conocido, sino también para darle un lugar que supere la expresión y lo reconozca como libre. Esto implica cuidar que los resultados de su investigación no reproduzcan, por falta de conciencia sobre las implicancias del conocimiento, relaciones de desigualdad (Vasilachis, 2007: I4).

Desde esta epistemología pueden producirse lo que se denomina procesos de «re», que van desde la resistencia hasta la redefinición de la propia identidad frente a las representaciones creadas en torno a ellos (Vasilachis, 2007: 2I). Procesos de redefinición discursiva que nosotros encontramos en la expresión de uno de los grupos que bajo la técnica taller expresó en una síntesis creativa la resistencia ante la mirada de la Dirección de Inteligencia de la Policía de la Provincia de Buenos Aires: «nos magullaron pero no nos quebraron». Frase elegida por el equipo de extensión para titular la publicación colectiva.

\section{El otro extensionista}

Para tomar recaudos e intentar sortear tanto la objetivización del otro disciplinar como del otro a conocer, debemos repensar algunas de las dificultades específicas de la construcción de la interdisciplina en los proyectos de investigación-acción enmarcados en la extensión universitaria. Así, la metodóloga de origen uruguayo Susana Rudolf (20I0) nos recuerda que para prevenir lo que describe como una tentación original omnipotente de las disciplinas, debemos favorecer un diálogo horizontal y permanente con la gente que no es de «nuestro club» dado que todos los clubes «ciegan» para cosas que sólo ven los de afuera.

En el caso de nuestro proyecto, incentivamos un diálogo interdisciplinar con miras a repensar las prácticas de construcción de saber-acción, saber-poder entre los distintos voceros disciplinares que integraban nuestro equipo — los/as representantes de historia, sociología, comunicación social, archivística, informática y artes visuales- y así replantearnos cuestiones implícitas en las distintas formaciones académicas y prácticas naturalizadas. Como en otros vínculos y relaciones sociales, en los vínculos interdisciplinares éramos conscientes que estaba implícito el tema del poder (Rudolf, 20I0: 85).

Para los proyectos de extensión, construir interdisciplina excede la justificación clásica de hacerlo porque se está frente a una realidad compleja. Y nos 
acerca a una perspectiva más terrenal — no por eso sencilla- donde debemos aceptar que además de existir diversos criterios y formas de comprensión de los fenómenos sociales, también estamos frente a sujetos «de transferencia», quienes atribuirán a cada profesional matices diversos, así como distintas expectativas. Para Rudolf estamos frente a una oportunidad privilegiada de intentar romper con la «endociencia», a fin de incluir los saberes de los/as ciudadanos/as, sin que esto implique diluir una productiva distinción entre disciplinas científicas y saber popular.

\section{Una mirada situada, preguntas localizadas}

Como toda visión de mundo, las distintas disciplinas —en tanto discursos de saber que reclaman legitimidad para sus proposiciones cognitivas- necesariamente adoptan una posición de transmisión de sus conocimientos y pareceres, al menos en principio con las otras disciplinas del campo común en ciencias sociales. La tendencia contemporánea exige cada vez más generar una difusión de las reflexiones analíticas que sin duda deben conmover las creencias previas sobre una posición neutral de los/as investigadores/as frente a la producción de sus distintos saberes teórico-prácticos.

Nos interesa compartir las reflexiones que autoras, desde la perspectiva de género, aportan para localizar a los/as investigadores sociales. En este sentido es que el concepto de locus excéntrico ilumina la necesaria revisión de miradas canónicas que defienden una posición del sujeto cognoscente falaz, un sujeto de conocimiento como observador neutral.

El locus excéntrico exige como condición de posibilidad desplazarnos de las coordenadas de construcción clásica de conocimiento científico a fin de constituir una práctica cognoscitiva que, en tanto locus excéntrico, tome en cuenta la variabilidad y el cambio en las acciones humanas, como volver consciente la excentricidad, abandonando así la pretensión de «ningún lugar objetivo» hacia lo que Dona Haraway denominó un saber situado. A través de este concepto la autora insiste en señalar que hay en toda mirada una naturaleza corporizada y en consecuencia un cuerpo marcado que la sostiene.

No estamos frente a una solución reduccionista ya que para la bióloga-filósofa un saber «situado» no se opone a un saber «objetivo». Localizarnos exige una práctica de desplazamientos desde los saberes hegemónicos (y o canóni$\cos$ ) hacia el rechazo a la escisión sujeto-objeto. Sólo así lograremos situarnos donde justamente la parcialidad (de la mirada) será condición para que las 
proposiciones de saber racional puedan plantearse, entenderse y solucionarse (Femenías y Soza Rossi, 20 I I: I 5).

En la misma sintonía, desde la epistemología del punto de vista de Dorothy Smith (Yañez, 20I I), los documentos de carácter histórico en nuestros talleres -en tanto textos que median relaciones de dominación-, además de ser una fuente de información sobre las organizaciones sociales, son también maneras de explorar y de ingresar en las prácticas cotidianas. Así, a través del relato de la experiencia emergen las relaciones sociales y/o la organización social en las que los/as narradores/as están inmersos/as.

Los interrogantes, cuestionamientos y reflexiones que guiaron la elaboración de los talleres retomaban la tensión entre la condición de trabajadores y los sectores dominantes. Y en ese sentido nos preguntábamos:

¿Quiénes eran los fichados? ¿Cuál era el criterio para ser fichado? Evidentemente que «te fichen» marcaba y marca una desigualdad de posiciones, que denota en parte una derrota. Pero también dice mucho sobre que por algo te miran. Porque potencialmente «el fichado» es parte de una disputa de poder. Y si bien el documento como las fichas concentran relaciones de poder desiguales por lo que «te hacen legajo», son cristalizaciones de esa relación de fuerzas; al mismo tiempo se nos presentan como un medio para deconstruir esa desigualdad. Había entonces que desnaturalizar los documentos que teníamos frente a nosotros, descongelarlos, para ver detrás de éstos a los actores que disputaban su parte de la verdad (Giménez y otros, 201 2: 66-67).

\section{Los espacios puentes: diálogo intergeneracional e intergénero}

Los espacios puentes son una alegoría que da cuenta de nuestra concepción de la relación entre el equipo de extensión universitaria y los/as integrantes del sindicato. Su denominación refiere a un camino que comunica espacios que están interrelacionados pero no necesariamente conectados. En este caso, intentamos generar un encuentro a partir de una doble vía de circulación de saberes, sentires y pensares mediante el ejercicio de la voz y el mutuo reconocimiento en tanto interlocutores de un posible diálogo.

La epistemología del punto de vista favoreció nuestra reflexión sobre el trabajo de extensión. Teniendo en cuenta la metáfora de Dorothy Smith (I996) sobre su experiencia como pasajera del tren, podemos decir que la metodolo- 
gía taller circunscribe la tendencia a la objetivación del otro, en tanto el marco cognitivo adoptado y el marco temporal que habilita un proyecto de extensión permiten imaginar múltiples oportunidades para bajar del tren y encontrarse con el otro. Si bien en el transcurso del proyecto fueron realizados dos talleres, llegar a esa instancia supuso una serie de reuniones previas con las referentes del sindicato donde la disposición a encontrarnos implicó de ambas partes un respeto mutuo por los tiempos lógicos de cada institución. Y, en este trayecto, al decir de Vasilachis, habilitamos la propia conmoción y la transformación del equipo de extensión en tanto sujeto cognoscente.

Éramos conscientes que reconocer al otro en sus múltiples diferencias suponía incorporar en la interacción comunicativa criterios de demarcación identitaria que influyen en la constitución de las distintas voces, como las categorías de género y generación.

Desnaturalizar los resabios biologicistas en la construcción social del conocimiento sobre el ser humano implica repensar al sexo y a la edad no como algo dado, sino como una construcción sociosimbólica que da significado a las distintas maneras de «estar en el mundo». En este sentido, las categorías de género y generación revolucionan el pensamiento científico (evitando el androcentrismo y el adultocentrismo), dando cuenta de distintas posiciones de habla que era lícito incluir en tanto enriquecían la referencia experiencial de los textos documentales elegidos para la dinámica de los talleres.

En paralelo a la necesidad de revisar las consecuencias del paradigma biológico en las ciencias sociales, la elección de diferenciar las experiencias de los trabajadores por género ${ }^{5}$ y generación ${ }^{6}$ respondió también a una demanda

5. El género da cuenta de la construcción social de la identidad sexual, en tanto dicha construcción asigna a las personas roles distintos, derechos, oportunidades, responsabilidades y expectativas de proyecto vital de acuerdo al sexo. Esto a partir del aspecto simbólico que se deriva de las implicancias asignadas desde lo social a un cuerpo marcado como femenino o masculino. Mientras el sexo sólo refiere a las diferencias biológicas entre varones y mujeres, sin explicar la existencia de estereotipos y normativas que se vuelven prescriptivas y limitantes para alcanzar la equidad entre los géneros.

6. La generación como categoría que supera la demarcación de la edad como dato biológico y refiere a cuestiones sociales o colectivas define un colectivo imaginario de personas que compartirán limitaciones y potencialidades epocales. A la demarcación histórica se añaden variaciones en las maneras de transitar el ciclo vital en tanto potencialidades y limitaciones que se inscriben en relación al adultocentrismo y al grupo de pares. Así dan un significado original a sus experiencias compartidas. No sólo 
concreta del sindicato. Las referentes consultadas mostraron interés en visibilizar la situación específica de las militantes sindicales y, al mismo tiempo, su intención de incorporar a los jóvenes en la tradición histórica de las modalidades de lucha sindical. En este sentido, citamos a dos referentes de la organización que destacaron especialmente la importancia del diálogo intergeneracional:

El vínculo entre las generaciones será indispensable para construir la memoria del sindicato y del pueblo entero.

Con ese objetivo en el horizonte es necesario construir una mirada histórica propia y combinarla con la fuerza rebelde de los jóvenes. Es la mejor manera de articular las experiencias del pasado con las del futuro (Giménez y otros, 2012).

En el caso de la categoría de género, distintas participantes expresaban una experiencia común: la carga emocional, el costo psíquico, que implicaba la práctica de militancia sindical, al tiempo que garantizar la organización del hogar, con el costo de ser "culpables» de cualquier desorden en el ámbito doméstico. A esta tensión subjetiva, Smith (2012) la llama conciencia bifurcada porque las mujeres deben realizar actividades en escenarios con lógicas distintas y hasta contrapuestas, que limitan su participación política anclándolas en la localidad doméstica.

Otra de las dificultades enunciada por las militantes remite a las relaciones de subalternidad al interior de la organización sindical. Un ejemplo paradigmático fue el esfuerzo de un grupo de mujeres militantes que, teniendo las condiciones de representación y habiendo perseverado en la afiliación sindical, evaluaban la resistencia a afiliarse por parte de sus compañeros varones, como producto de su condición de mujeres «ilegítimas representantes» en un ámbito laboral mayoritariamente masculino como la Fábrica Militar de Pólvoras y Explosivos de la Ciudad de Azul, Provincia de Buenos Aires, Argentina.

En estos ejemplos queda expresado cómo la dicotomía productivo-reproductivo incidió históricamente en el ideal de trabajador como varón proveedor y cómo eso, más allá de las transformaciones históricas, incidía en la subvaloración del aporte de las mujeres a la constitución de las acciones sindicales, sea desde las limitaciones de tiempo disponible frente a una democratización

compartirán experiencias, sino también formas de pensamiento y un tipo particular de acción histórica relevante. 
escasa de las tareas de reproducción doméstica y de la fuerza de trabajo o desde la invisibilización que implica comprender la fuerza de acción sindical sólo atendiendo a los dirigentes formales, en su mayoría aún varones.

En relación a los/las jóvenes, la mirada adultocéntrica que se centra en el preconcepto de la juventud como motor de cambio social, les asigna la responsabilidad de la transformación de lo «no hecho»y, al mismo tiempo, una visión que transmite que quien tiene el saber legítimo es sólo quien vivió los acontecimientos. Esta perspectiva cercenaba las otras maneras de pensar los acontecimientos pasados y las acciones sindicales presentes y futuras.

\section{Consideraciones finales}

De los conceptos no podemos recoger y sacar más que lo que hemos puesto en ellos [...] y, con ellos, no podemos hacer otra cosa que echar puentes sobre el río caudaloso de la realidad, por diminutos que sean los ojos de esos puentes.

H. Rickert, Citado en Fals Borda (I979: 269)

Las reflexiones de Rudolf (2010) sobre la trayectoria de un Programa de Extensión en Uruguay nos ayudaron a reflexionar en retrospectiva sobre los obstáculos y elementos facilitadores presentes en nuestra experiencia de investigación-acción. Creemos que estas líneas pueden aportar al desarrollo futuro de otras experiencias de extensión que tomen como marco de acción a la IAP.

Entre los obstáculos nos encontramos, en primer lugar, con un acceso restringido a materiales de teorías críticas alternativas y metodologías dialógicas. Ya sea por su escasa presencia en los currículos de formación en las distintas disciplinas de las ciencias sociales, como por una circulación fluida en el eje académico norte-sur, en detrimento del eje sur-sur; por ejemplo, nos encontramos con la paradoja de conocer la bibliografía falsbordiana desde editoriales españolas.

Otra de las dificultades a las que nos enfrentamos fue la escasa sistematización y publicación de las complejidades de construir interdisciplina en proyectos de extensión. Así, tuvimos que ir construyendo nuestras propias reflexiones sin ninguna referencia a estrategias de superación del quehacer extensionista. A esto se sumaban las tensiones propias de la convivencia en el equipo de extensión de disciplinas con estatus de legitimidad académica diferenciales: el aprender a expresar nuestras divergencias sin temor a disensos irreconciliables que pusieran en peligro el proyecto. 
Por otro lado, identificamos algunos elementos que facilitaron nuestra tarea y el sostenimiento en el largo plazo del compromiso extensionista. Uno de ellos fue la común trayectoria laboral en tanto trabajadores de la CPM. Otro, nuestra formación predominante dentro del campo de las ciencias sociales y la capacitación común en archivística, lo cual nos permitió valorar el acervo documental en su contexto de producción. A lo cual se suma un acuerdo ideológico-cognitivo con cimientos en la afectividad al interior del equipo y con los/as compañeros/as del sindicato.

Este último punto fue central para retomar luego de un impasse el compromiso de concretar la publicación que permitiera, por un lado, la sistematización necesaria para futuras replicas de la experiencia y, por otro, una devolución a los/as trabajadores/as.

Situadas en la escritura de este trabajo, transcurrido un intervalo de tiempo significativo desde la experiencia de los talleres y la elaboración colectiva de la publicación final, consideramos que, aún con limitaciones, logramos construir un marco cognitivo común que, desde el diálogo interdisciplinar, favoreció el encuentro con los/as trabajadores/as del sindicato. Un encuentro donde los distintos sujetos participantes estuvieron dispuestos a escucharse y conmoverse. Aún resuena en nuestra memoria la frase que utilizaran para referirse a nosotros/as: «acá vienen los/as compañeros/as de extensión».

\section{Referencias}

Benhabib, Seyla (2006). Las reivindicaciones de la cultura: Igualdad y diversidad en la era global. Buenos Aires: Katz.

Bralich, Jorge (I994). Educación popular. Historia y conceptualización. Montevideo: EPPAL.

FALS BORDA, Orlando (I979). «Cómo investigar la realidad para transformarla». En El problema de cómo investigar la realidad para transformarla. Bogotá: Tercer Mundo.

-. (2008). «La investigación acción en convergencias disciplinarias». Disponible en <http://historiactualdos.blogspot.com.ar/2008/I I/la-investigacinaccin-en-convergencias.html>.

Femenías, María Luisa y Paula Soza Rossi (20I I). "Para una mirada de género situada al sur». En María Luisa Femenías y Paula Soza Rossi (comp.), Saberes situados/Teorías trashumantes. Editorial de la Facultad de Humanidades y Ciencias de la Educación. Idihcs-Cinig. 
Freire, Paulo (1985). Pedagogía del oprimido. Buenos Aires: Siglo XXI.

-. (200I). Extensión o comunicación. México: Siglo XXI.

Giménez, Sebastián, Lucía Trotta, Paula Soza Rossi, Carolina Salvador, Santiago Cueto Rua y Viviana Doba (2012). Nos magullaron pero no nos quebraron: Los sindicatos bajo la mirada de la DIPBA. Experiencia de extensión universitaria con ATE Provincia. La Plata: Universidad Nacional de La Plata, Facultad de Humanidades y Ciencias de la Educación.

Krotsch, P. (200I). Educación y reformas comparadas. Buenos Aires: Universidad Nacional de Quilmes, Colección Cuadernos.

LuCARelli, Elisa (2000). Estrategias didácticas de enseñanza y evaluación. Programa de Formación Docente Continua. Programa de Publicaciones. Serie Conferencias y Clases Plenarias. Secretaría General Académica. Rectorado, Universidad Nacional del Nordeste.

Ortiz, Marielsa y Beatriz BorJas (2008). «La investigación-acción participativa: aporte de Fals Borda a la educación popular». Espacio Abierto, I 7 (4): 6I 5-627. Disponible en <http://redalyc.uaemex.mx/src/inicio/ArtPdfRed. jsp?iCve $=\mathrm{I} 22 \mathrm{I} 7404>$.

Puiggrós, Adriana (I987). «Alfabetizar es participar». En Discusiones sobre educación y política. Buenos Aires: Galerna.

Rudolf, Susana (2010). «La interdisciplina en los procesos de extensión». En La extensión en obra. Uruguay: Editorial Extensión Universidad de la República

Smith, Dorothy (I996). "Problematizar el mundo cotidiano: un método feminista». En Ágata Gligo (ed.), El mundo silenciado de las mujeres (pp. I35-I79). Santiago: CIDE.

-. (20I2). «El punto de vista (Standpoint) de las mujeres: conocimiento encarnado versus relaciones de dominación». Revista del CEHIM, 8 (8).

Tunnermann Bernheim, Carolina (200I). "El nuevo concepto de extensión universitaria». En Memorias V Congreso Iberoamericano de Extensión, «Sociedad, Educación Superior y Extensión: Balance y perspectivas». México: ANUIES. Colección Documentos. Disponible en $<$ http://www.udea.edu. co/portal/page/portal/BibliotecaPortal/InformacionInstitucional/Autoevaluacion/SistemaUniversitarioExtension/NuevoConceptoExtensionUniversitaria-CarlosTunnermann.pdf>.

VASILACHIS, Irene (2007). «El aporte de la epistemología del sujeto conocido al estudio cualitativo de las situaciones de pobreza, de la identidad y de las representaciones sociales». En Forum: Qualitative Social Research, 8 (3). 
YaÑEZ, Sabrina (20II). «Develando la propuesta de Dorothy Smith: aportes epistemológicos y metodológicos para el abordaje de lo social». En Revista Diálogos (Universidad Nacional de San Luis), 2 (I): I I I-I 26.

\section{Sobre las autoras}

Lucía Trotta es licenciada en Sociología por la Universidad Nacional de La Plata (UNLP), Argentina. Maestranda en Ciencias Sociales con Orientación en Educación, Flacso, Argentina. Docente e investigadora del Departamento de Ciencias de la Educación y del Departamento de Sociología de la UNLP. Su correo electrónico es <luciatrotta_e@yahoo.com.ar>.

Paula Soza Rossi es licenciada en Sociología por la Universidad Nacional de La Plata (UNLP), Argentina. Maestranda en Género, Sociedad y Políticas, Prigepp, Flacso, Argentina. Docente e investigadora del Centro Interdisciplinario de Investigaciones en Género y del Departamento de Sociología de la UNLP. Su correo electrónico es < paulasoza11@yahoo.com.ar>. 